\title{
Analysis of $\alpha$-Linolenic Acid Biohydrogenation Intermediates in Milk Fat with Emphasis on Conjugated Linolenic Acids
}

\author{
F. Destaillats, ${ }^{1, \star}$ J. P. Trottier, ${ }^{1}$ J. M. G. Galvez, ${ }^{2}$ and P. Angers ${ }^{1}$ \\ ${ }^{1}$ Department of Food Science and Nutrition, and Dairy Research Center (STELA), Université Laval, \\ Sainte Foy, Québec, Canada, G1K 7P4 \\ ${ }^{2}$ Naturia Inc., 4220, Rue Garlock, Sherbrooke, Québec, Canada, J1L 2P4
}

\begin{abstract}
Ruminal biohydrogenation of $\alpha$-linolenic acid is not fully understood compared with that of linoleic acid. Some hypothetical intermediates, that is, conjugated isomers of $\alpha$-linolenic acid (cis-9,trans-11,cis-15 and cis9,trans-13,cis-15 18:3) have never been reported to occur in ruminant fat. Therefore, milk fat was analyzed using a combination of techniques to characterize $\alpha$ linolenic acid biohydrogenation intermediates. Tandem off-line argentation thin-layer chromatography and high-resolution gas-liquid chromatography using a 120$\mathrm{m}$ highly polar, open tubular capillary column coated with $70 \%$ cyanoalkyl polysiloxane equivalent material was used for quantification. Structural characterization of fatty acids was achieved by gas-chromatography mass-spectrometry after synthesis of specific azo-derivatives. This study confirmed that minute amounts of $\alpha$-linolenic acid biohydrogenation intermediates are present in milk fat. Routes involved in biohydrogenation of linoleic and $\alpha$-linolenic acids in the rumen and subsequent endogenous metabolism of related biohydrogenation products are discussed.
\end{abstract}

(Key words: biohydrogenation, conjugated linolenic acid, milk fat, rumelenic acid)

Abbreviation key: CLA = conjugated linoleic acid, DMOX = 4,4-dimethyloxazoline, FA = fatty acid, FAME = fatty acid methyl esters, GC-MS = gas chromatography-mass spectrometry.

\section{INTRODUCTION}

Biohydrogenation of linoleic and $\alpha$-linolenic acids give rise to accumulation of minor fatty acids (FA) in ruminant fat (Bauman and Griinari, 2003). In this

Received November 20, 2004.

Accepted April 13, 2005.

Corresponding author: Paul Angers; e-mail: paul.angers@fsaa. ulaval.ca.

*Present address: Nestlé Research Centre, Quality and Safety Department, Vers-chez-les-Blanc, PO Box 44, CH-1000 Lausanne 26, Switzerland. group, the most abundant natural isomer is rumenic (cis-9,trans-11 18:2) acid, a conjugated linoleic acid (CLA) widely found in dairy, ruminant meat, and related products (Banni and Martin, 1998). Conjugated linoleic acid refers to several positional and geometrical isomers of linoleic (cis-9,cis-12 18:2) acid comprising a conjugated ethylenic double bond system. Rumenic acid is naturally formed both by anaerobic biohydrogenation of linoleic acid in the rumen (Bauman and Griinari, 2003) and by $\Delta^{9}$-desaturation of vaccenic (trans-11 18:1) acid in animal cells (Adlof et al., 2000; Griinari et al., 2000; Santora et al., 2000).

An enzyme, the $\Delta^{12}$-cis, $\Delta^{11}$-trans-isomerase implicated in the biohydrogenation process, was partially purified from Butyrivibrio fibrisolvens in the 1960s (Kepler et al., 1966; Kepler and Tove, 1967). These authors have shown that the biohydrogenation pathway of $B$. fibrisolvens included isomerization of linoleic acid into rumenic acid. It was later demonstrated that in $B$. fibrisolvens, rumenic acid is subsequently reduced to vaccenic (trans-11 18:1) acid by a second enzyme, CLA reductase (Hughes et al., 1982). $\alpha$-Linolenic (cis-9,cis12,cis-15 18:3) acid has also been studied as a model substrate for $\Delta^{12}$-cis, $\Delta^{11}$-trans-isomerase (Kepler and Tove, 1967). It has been shown that $\alpha$-linolenic acid is transformed into a partially conjugated FA tentatively assigned a cis-9,trans-11,cis-15 18:3 acid structure, which remains to be confirmed (Wilde and Dawson, 1966; Kepler and Tove, 1967). It was found that this conjugated FA is subsequently reduced into a nonconjugated cis,trans dienoic FA by the partially purified enzyme, isolated from $B$. fibrisolvens (Kepler and Tove, 1967). These authors concluded that biohydrogenation of $\alpha$-linolenic acid by $B$. fibrisolvens was similar to that of linoleic acid, and as such, the presence of a $\Delta^{15}$ ethylenic double bond had little or no effect on the biohydrogenation process (Kepler and Tove, 1967).

The main objective of the present study was to analyze milk fat for biohydrogenation intermediates of $\alpha$ linolenic acid, to provide analytical evidence that the first event of this biological process is catalyzed by the same enzyme as linoleic acid, as proposed $40 \mathrm{yr}$ ago. The second objective was to complete a biosynthetic 
pathway for biohydrogenation of $\alpha$-linolenic and linoleic acids in the rumen that would be consistent with literature data (Kepler et al., 1966; Wilde and Dawson, 1966; Kepler and Tove, 1967; Hughes et al., 1982; Ulberth and Henninger, 1994; Griinari et al., 2000; Corl et al., 2002; Loor et al., 2004; 2005a,b).

\section{MATERIALS AND METHODS}

\section{Samples and Reagents}

A mixture of cis-9,trans-11,cis-15 and cis-9,trans13,cis-15 18:3 acid isomers was kindly donated by Naturia Inc. (Sherbrooke, QC, Canada); methyl linoleate and methyl cis-11,cis-14 eicosadienoate were obtained from Nu-Chek Prep (Elysian, MN). Silver nitrate, potassium tert-butoxide (1.0 $\mathrm{M}$ in tetrahydrofuran), 3-pyridylcarbinol, and 2-amino-2-methyl-1-propanol were purchased from Aldrich Chemicals (Milwaukee, WI).

\section{Milk Fat Extraction}

Milk fat was extracted from full-fat summer cream (purchased locally in Québec, QC, Canada) according to a published procedure (Wolff, 1995) using hexane/ isopropanol $(3: 2, \mathrm{vol} / \mathrm{vol})$ with minor modifications. A representative sample ( $\sim 10 \mathrm{~g})$ was dispersed in isopropanol $(50 \mathrm{~mL})$ and, after addition of hexane $(75 \mathrm{~mL})$, a second dispersion was carried out. The suspension was filtered, transferred into a separatory funnel, and washed with an aqueous solution of sodium chloride ( $5 \% \mathrm{wt} / \mathrm{vol}, 2 \times 100 \mathrm{~mL}$ ). The organic phase was dried over anhydrous sodium sulfate, filtered, and the solvents were removed in a rotary evaporator at $45^{\circ} \mathrm{C}$ under vacuum. The lipid extract was stored at $-18^{\circ} \mathrm{C}$ until use.

\section{Fatty Acid Methyl Ester Synthesis}

Methylation of $o$-acetylated milk fat FA $(\sim 20 \mathrm{mg}$ in $2 \mathrm{~mL}$ of hexane) was carried out in a sealed tube with $0.4 \mathrm{~N}$ sodium methoxide in methanol $(0.5 \mathrm{~mL})$. After homogenization, the mixture was held at $40^{\circ} \mathrm{C}$ for 15 min, cooled to room temperature $\left(25^{\circ} \mathrm{C}\right)$, washed with water $(1 \mathrm{~mL}$; vortexed for $\sim 5 \mathrm{~s}$, allowed to stand for 1 min), and FA methyl esters (FAME) were extracted with hexane $(3 \times 1 \mathrm{~mL})$. The organic extracts were combined, dried over anhydrous sodium sulfate, filtered, and kept under $\mathrm{N}_{2}$ in closed vials at $-18^{\circ} \mathrm{C}$ until analysis.

\section{Fractionation of FAME by Ag-TLC}

Fatty acid methyl esters were fractionated by TLC on silica gel plates impregnated with silver nitrate
$\left(\mathrm{AgNO}_{3}\right)$. The plates were immersed in a $5 \%$ silver nitrate solution in acetonitrile for $15 \mathrm{~min}$ in the dark, and activated at $100^{\circ} \mathrm{C}$ for $1 \mathrm{~h}$ (Wolff, 1995). Fractionation was performed according to number and configuration of double bonds, using a mixture of hexane and diethyl ether $(80: 20, \mathrm{vol} / \mathrm{vol})$ as developing solvent. At the end of the chromatographic runs, the plates were sprayed with a solution of $2^{\prime}, 7^{\prime}$-dichlorofluorescein, and viewed under UV light. A mixture of cis-9,trans-11,cis15 and cis-9,trans-13,cis-15 18:3 acids was used as a standard. A band corresponding to dienoic FAME $\left(\mathrm{R}_{\mathrm{f}}=\right.$ 0.52 ) was scraped off and transferred to a test tube; methanol $(1.5 \mathrm{~mL})$, hexane $(2 \mathrm{~mL})$, and an aqueous solution of sodium chloride $(5 \% \mathrm{wt} / \mathrm{vol}, 1.5 \mathrm{~mL})$ were successively added with thorough mixing after each addition. After standing for $\sim 1 \mathrm{~min}$, the hexane phase was withdrawn, and the sample was concentrated before GLC analysis.

\section{GLC Analysis of FAME}

Analysis of total FAME and Ag-TLC fractions were performed on a 5890 Series II gas chromatograph (Hewlett-Packard, Palo Alto, CA), equipped with a fused silica BPX-70 capillary column (equivalent to $70 \%$ cyanopropyl; $120 \mathrm{~m}, 0.25 \mathrm{~mm}$ i.d., $0.25 \mu \mathrm{m}$ film thickness; SGE, Melbourne, Australia), and connected to a ChemStation (Hewlett-Packard). Injection (split mode) and detection (flame-ionization) were performed at $250^{\circ} \mathrm{C}$. Oven temperature programming was $60^{\circ} \mathrm{C}$ isothermal for $1 \mathrm{~min}$, increased to $170^{\circ} \mathrm{C}$ at $20^{\circ} \mathrm{C} / \mathrm{min}$, and held for $60 \mathrm{~min}$ at $170^{\circ} \mathrm{C}$. The inlet pressure of the carrier gas $\left(\mathrm{H}_{2}\right)$ was $300 \mathrm{kPa}$ at $170^{\circ} \mathrm{C}$.

\section{Preparation of Picolinyl Ester Derivatives}

Picolinyl esters of FA were prepared directly from intact milk lipids according to a published procedure (Destaillats and Angers, 2002a). A solution of potassium tert-butoxide in tetrahydrofuran $(100 \mu \mathrm{L}, 1.0$ $M)$ was added to 3-pyridylcarbinol $(200 \mu \mathrm{L})$. After homogenization, milk fat $(10 \mathrm{mg})$ solution in methylene chloride $(1 \mathrm{~mL})$ was added to the reaction, and the mixture was maintained at $40^{\circ} \mathrm{C}$ for $15 \mathrm{~min}$ in a closed vial with occasional stirring. After cooling to room temperature $\left(25^{\circ} \mathrm{C}\right)$, the reaction mixture was washed with distilled water $(1 \mathrm{~mL})$, and the organic phase was withdrawn, dried over anhydrous sodium sulfate, and filtered prior to gas chromatography-mass spectrometry (GC-MS) analysis.

\section{Preparation of 4,4-Dimethyloxazoline Derivatives}

4,4-Dimethyloxazoline (DMOX) derivatives of FA were prepared using a modified published procedure 
(Garrido and Medina, 1994) by heating milk fat (10 mg) directly with 2-amino-2-methyl-1-propanol $(500 \mu \mathrm{L})$ under nitrogen atmosphere at $150^{\circ} \mathrm{C}$ overnight. The temperature was accurately controlled to prevent sigmatropic rearrangements of conjugated FA that readily occur at higher temperatures (i.e., $\geq 170^{\circ} \mathrm{C}$; Destaillats and Angers, 2002b).

\section{GC-MS Analysis}

Fatty acid picolinyl esters and DMOX derivatives were analyzed by GC-MS (Hewlett-Packard model 6890 Series II gas chromatograph attached to an Agilent model $5973 \mathrm{~N}$ selective quadrupole mass detector) under an ionization voltage of $70 \mathrm{eV}$ at $230^{\circ} \mathrm{C}$, and connected to a computer with a Hewlett-Packard ChemStation. The injector (split mode) and the interface temperatures were maintained at $250^{\circ} \mathrm{C}$, and $\mathrm{He}$ was used as carrier gas under constant flow ( $1 \mathrm{~mL} / \mathrm{min})$. Gas-liquid chromatography separation was performed on a BPX70 capillary column (SGE, Melbourne, Australia; $60 \mathrm{~m}$, $0.25 \mathrm{~mm}$ i.d., $0.25 \mu \mathrm{m}$ film thickness). For picolinyl esters, the following temperature programming mode was used: $200^{\circ} \mathrm{C}$ isothermal for $10 \mathrm{~min}$; increased to $230^{\circ} \mathrm{C}$ at $5^{\circ} \mathrm{C} / \mathrm{min}$; isothermal at this temperature for $40 \mathrm{~min}$; then increased to $260^{\circ} \mathrm{C}$ at $5^{\circ} \mathrm{C} / \mathrm{min}$; and isothermal at $260^{\circ} \mathrm{C}$ for $5 \mathrm{~min}$. For DMOX derivatives, the programming mode consisted of $60^{\circ} \mathrm{C}$ isothermal for 1 min; increased to $170^{\circ} \mathrm{C}$ at $20^{\circ} \mathrm{C} / \mathrm{min}$; and held isothermal for $60 \mathrm{~min}$ at $170^{\circ} \mathrm{C}$. Interpretation of mass spectra was performed according to published guidelines (Christie, 1998).

\section{RESULTS AND DISCUSSION}

\section{Tentative Identification of Conjugated Isomers of $\alpha$-Linolenic Acid: Rumelenic and Isorumelenic Acids}

Milk fat was quantitatively extracted from Canadian summer milk cream, and FAME were prepared by basecatalyzed methanolysis. Gas-liquid chromatography analysis was performed using a very long polar capillary column to analyze the complex chromatographic zone ranging from methyl linoleate to methyl eicosadienoate (Figure 1A). The resulting chromatogram (Figure 1B) showed, however, overlapping peaks of FAME ranging from methyl trans-octadecenoate to methyl linoleate. The product from initial biohydrogenation of $\alpha$ linolenic acid by $B$. fibrisolvens had been tentatively assigned the cis-9,trans-11,cis-15 18:3 acid structure (Kepler and Tove, 1967). Analysis of the mixture of cis-9,trans-11,cis-15 18:3 and cis-9,trans-13,cis-15 18:3 acid isomers revealed that these 2 analytes coeluted under the experimental conditions used. To resolve these 2 isomers by GLC, several experiments were performed using different temperature programming or different stationary phases without obtaining any significant peak separation. The unknown peak, which can correspond to the product identified in literature as cis-9,trans-11,cis-15 18:3 acid (Kepler and Tove, 1967), eluted with a retention time similar to that of the 2 synthetic conjugated isomers of $\alpha$-linolenic acid.

Formal confirmation of the structure was achieved using GC-MS analysis of both its picolinyl ester and DMOX derivatives prepared from total lipid extract. The use of azo-derivatives is a necessary step before structural determination of fatty acids by GC-MS because mass spectra of FAME, the usual derivatives for GLC analysis, are devoid of sufficient information for identification of structural isomers. This is mainly due to the high sensitivity of the carboxyl group to fragmentation and to double bond migration (Christie, 1998). However, stabilization of the carboxyl group by the formation of a derivative containing a nitrogen atom results in mass spectra that allow structural determination for most fatty acids. The mass spectrum of DMOX derivative of cis-9,trans-11,cis-15 18:3 acid (Figure 2A) indicated a molecular ion at $\mathrm{m} / \mathrm{z} 331$, confirming the octadecatrienoic acid structure. The strong ion at $\mathrm{m} / \mathrm{z}$ 262 confirmed the location of the 11,15-double bond system; such a strong ion fragment is usually observed from bis-methylene interrupted FA, resulting in the facilitated formation of 2 stabilized allylic radical fragments (Christie, 1998; Wolff and Christie, 2002). Moreover, gaps of $12 \mathrm{amu}$ between m/z 196 and 208, and 276 and 288 confirmed the location of double bonds in positions 9 and 15, respectively (Christie, 1998). Sequential gaps of $14 \mathrm{amu}$ from 196 down to 126 indicated the presence of methylene groups from $\mathrm{C}_{8}$ down to $\mathrm{C}_{3}$. The mass spectrum of the picolinyl ester derivative (Figure 2B) corroborated this structure identification. Indeed, ion at $\mathrm{m} / \mathrm{z} 300$ confirmed the location of the 11,15-double bond system, and gaps of 26 amu between $\mathrm{m} / \mathrm{z} 234$ and 260 , and 314 and 340 verified the location of double bonds in positions 9 and 15, respectively (Christie, 1998). The occurrence of ions at $\mathrm{m} / \mathrm{z}=236$ (Figure 2A) and at $\mathrm{m} / \mathrm{z}$ 275/276 (Figure 2B) provides evidence for the occurrence of a small amount of the cis-9,trans-13,cis-15 18:3 acid isomer. Indeed, these 2 ion fragments can correspond to a cleavage at the center of the 9,13 double bond system. Distinct GC-MS analysis of the synthetic mixture as their picolinyl esters and DMOX derivatives revealed the occurrence of these ion fragments. An approximation of the relative abundance of the 2 conjugated isomers, based on relative abundance of ion fragments at $\mathrm{m} / \mathrm{z} 262 / 236$ (Figure 2A) and ion fragments at $\mathrm{m} / \mathrm{z} 300 / 276-275$ (Figure 2B), indicates a 4:1 ratio between cis-9,trans-11,cis-15 and cis-9,trans- 


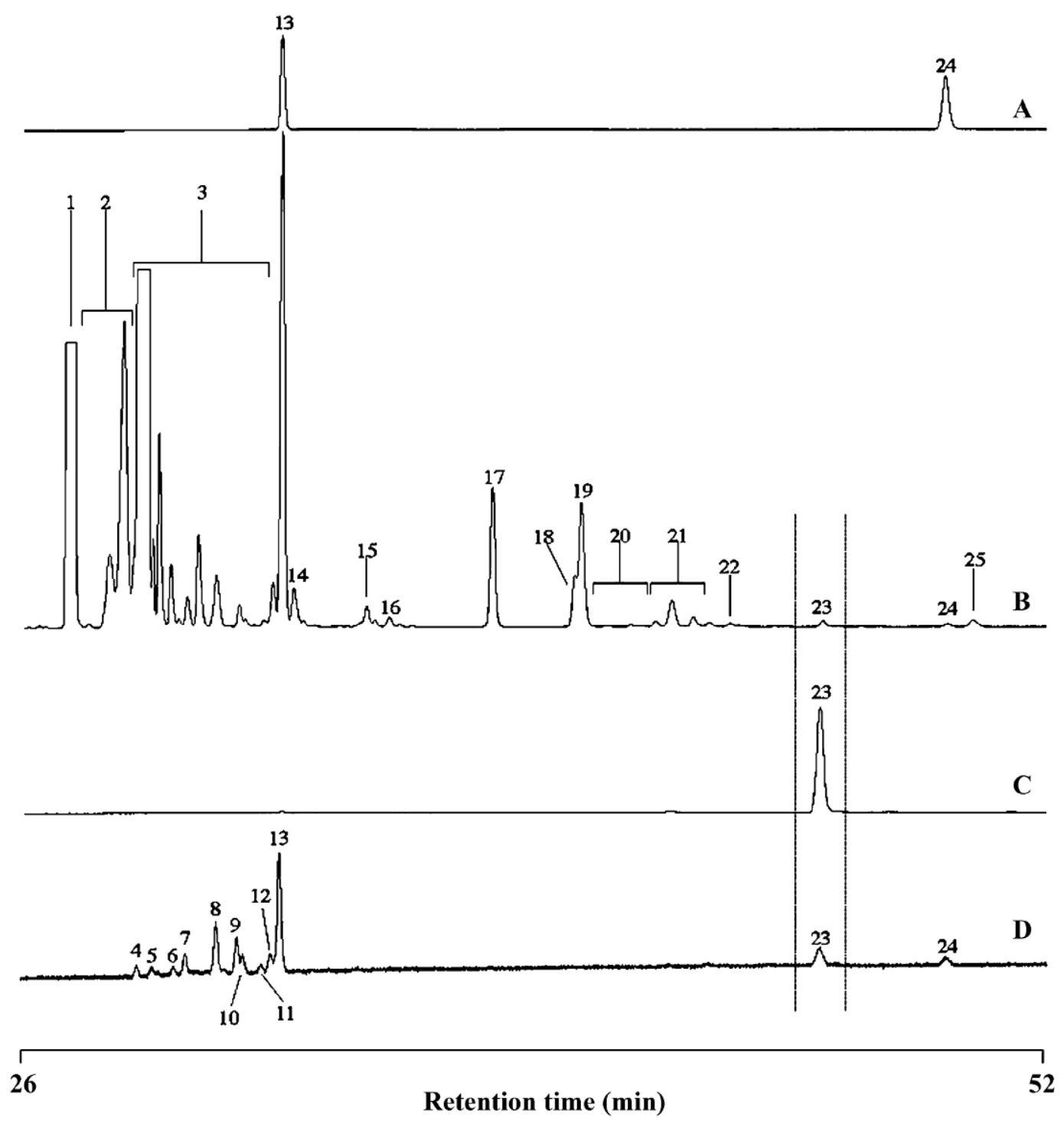

Figure 1. Gas-liquid chromatograms of fatty acid methyl ester (FAME) derivatives of (A) standards of cis-9,cis-12 18:2 (linoleic) and cis11,cis-14 20:2 acids; (B) milk fat fatty acids; (C) standard of cis-9,trans-11,cis-15 18:3 (rumelenic) acid; and (D) FA from argentation TLC fraction of milk fat FAME. Chromatograms were obtained using a 120-m BPX-70 capillary column on temperature programming mode (see Materials and Methods for detailed procedure). Peak identification (FAME): 1 (18:0); 2 (trans-4 to trans-11 18:1 isomers); 3 (overlapping zone containing trans-12 to trans-16 18:1 isomers, cis-6 to cis-15 18:1 isomers, 19:0 and cis/trans-18:2 isomers); 4-7 (trans,trans 18:2 isomers); 8 (cis-9,trans-13 18:2); 9-11 trans-8,cis-13 18:2, cis-9,trans-12 18:2, trans-9,cis-12 18:2 (precise elution order not determined); 12 (trans11,cis-15 18:2); 13 (cis-9,cis-12 18:2); 14 (cis-12,cis15-18:2 and cis-9 19:1); 15 (unidentified); 16 (cis-6,cis-9,cis-12 18:3); 17 (cis-9,cis-12,cis-15 18:3); 18 (20:0); 19 (cis-9,trans-11 18:2); 20 (cis/trans-CLA); 21 (cis,cis-CLA, 20:1 isomers and 21:0); 22 (trans,trans-CLA); 23 (tentatively identified cis-9,trans-11,cis-15 18:3); 24 (cis-11,cis-14 20:2); 25 (unidentified). For FAME 4 to 14, tentative identification was achieved using published analytical data obtained with a similar capillary column (Precht and Molkentin, 1997, 1999).

13,cis-15 18:3 acid isomers. Therefore, cis-9,trans11, cis-15 18:3 acid is the main conjugated isomer of $\alpha$ linolenic acid in milk fat.

These results tend to confirm the hypothesis previously proposed (Kepler and Tove, 1967; Wilde and Dawson, 1966) on the formation of cis-9,trans-11,cis-15 18:3 acid isomer during the biohydrogenation process of $\alpha$-linolenic acid by anaerobic bacteria, and its occur- rence in ruminant fats. This hypothesis was based on analogies between linoleic and $\alpha$-linolenic acids as substrates of the $\Delta^{12}$-cis, $\Delta^{11}$-trans-isomerase of $B$. fibrosolvens (Kepler and Tove, 1967), without regard to the cis-15 double bond. Linoleic acid is thus transformed into rumenic acid, whereas $\alpha$-linolenic acid should yield cis-9,trans-11,cis-15 18:3 acid isomer whose presence in milk fat we have now confirmed. We propose "rumelenic 

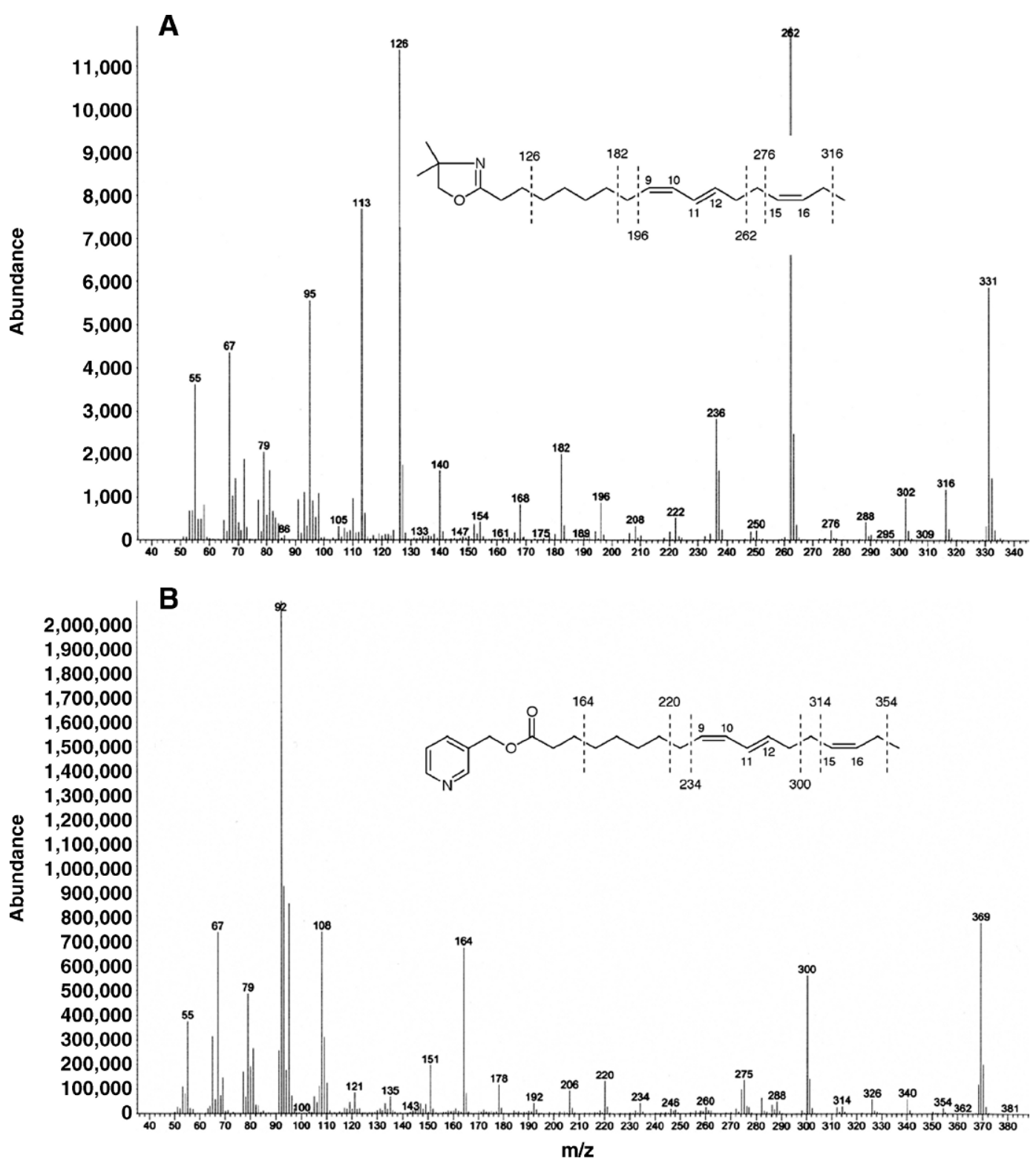

Figure 2. Mass spectra of (A) 4,4-dimethyloxazoline derivative; and (B) picolinyl ester derivative of cis-9,trans-11,cis-15 18:3 acid (rumelenic acid), obtained by gas chromatography-mass spectrometry analysis of milk fat fatty acids (see Materials and Methods for detailed procedure).

acid" as a trivial name, by reference to both rumenic (cis-9,trans-11 18:2; Kramer et al., 1998) and $\alpha$-linolenic (cis-9,cis-12,cis-15 18:3) acids. Additionally, we propose "isorumelenic acid" as a trivial name for cis-9,trans13,cis-15 18:3 acid. Results showed that rumelenic acid eluted close to dienoic FAME on Ag-TLC, in a manner similar to that of methyl CLA compared with methyl esters of monoenoic acids (Christie et al., 2001). Therefore, the present Ag-TLC experimental conditions are suitable for the isolation of partially conjugated trienoic and nonconjugated dienoic FA formed by biohydrogenation of polyunsaturated FA.
Analytical data related to the tentatively identified conjugated isomers of $\alpha$-linolenic acid have not been previously reported. However, conjugated FA have been of interest to researchers for over a century. Indeed, Hopkins reported in his review (Hopkins, 1972) that $\alpha$ eleostearic (cis-9,trans-11,trans-13 18:3) acid was first observed in the oil of Aleuriles cordata in 1887, and its definitive structure was established in 1953. In fact, before the 1980s, about 40 acids bearing conjugated unsaturation systems had been identified in seed oils. The most frequently encountered are fully conjugated octadecatrienoic acids, such as $\alpha$-eleostearic, but also 


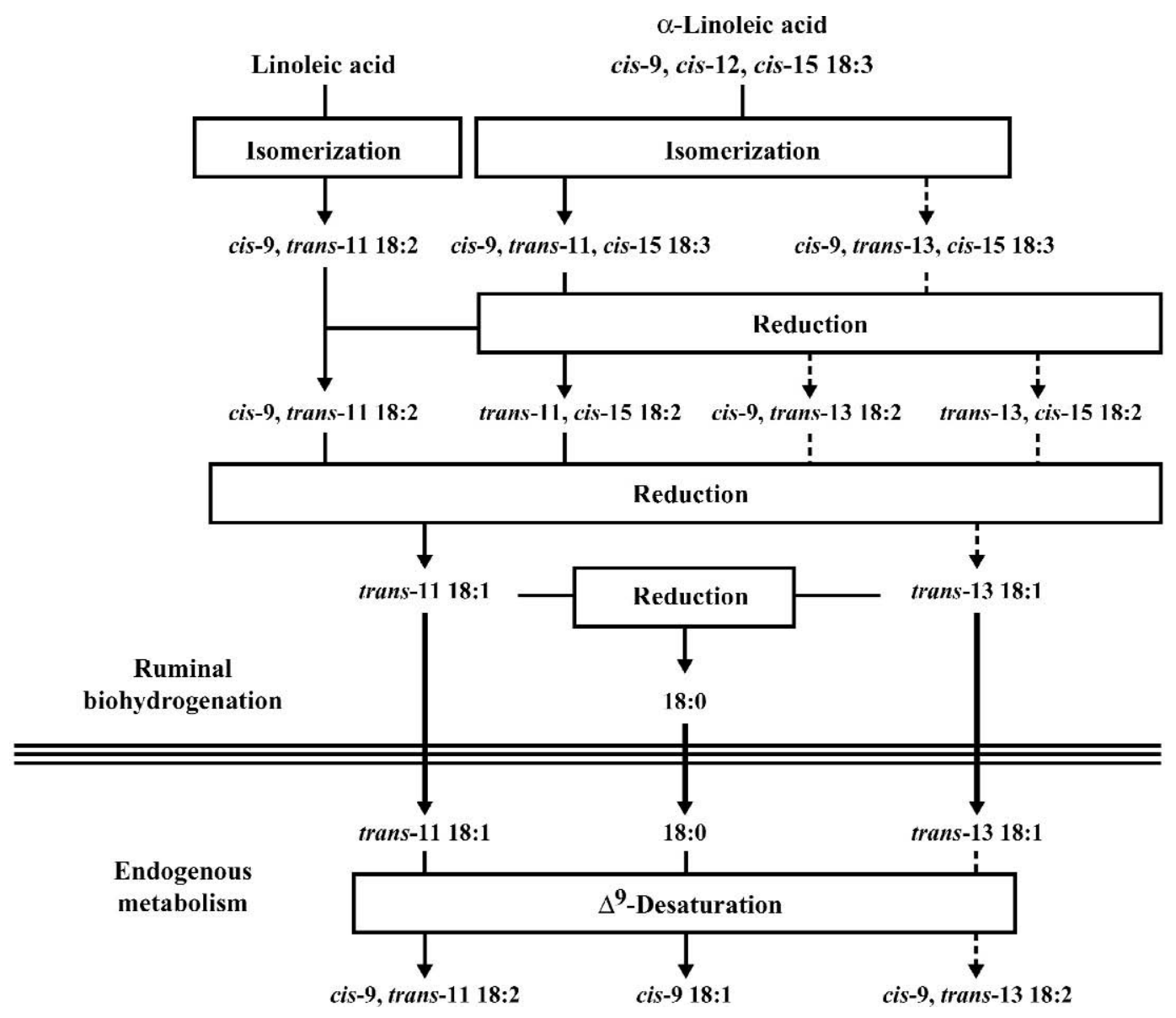

Figure 3. Ruminal biohydrogenation of linoleic (cis-9,cis-12 18:2) and $\alpha$-linolenic (cis-9,cis-12,cis-15 18:3) acids and subsequent endogenous $\Delta^{9}$-desaturation metabolism of stearic and trans-18:1 acids. Pathway established using published data (Kepler et al., 1966; Wilde and Dawson, 1966; Kepler and Tove, 1967; Hughes et al., 1982; Ulberth and Henninger, 1994; Griinari et al., 2000; Corl et al., 2002; Loor et al., 2004, 2005a,b; and the present study.

jacaric (cis-8,trans-10,cis-12 18:3), calendic (trans8,trans-10,cis-12 18:3), punicic (cis-9,trans-11,cis-13 18:3), and catalpic (trans-9,trans-11,cis-13 18:3) acids (Hopkins, 1972).

\section{Identification of Further $\alpha$-Linolenic Acid Biohydrogenation Intermediates}

Moving down the biohydrogenation scheme (Figure 3 ), it is well known that reduction of rumenic acid provides vaccenic (trans-11 18:2) acid (Hughes et al., 1982). By analogy, rumelenic acid should be further transformed into trans-11,cis-15 18:2 acid, as shown in Figure 3. Detailed analysis by GC-MS of the chromatographic zone ranging from FA 9 to 13 (Figure 1D) as their picolinyl esters has indeed allowed confirmation for the occurrence of at least 2 bis-methylene interrupted FA. The mass spectrum of the picolinyl ester derivative of FA 12 (trans-11,cis-15 18:2 acid) is illus- trated in Figure 4A. Molecular ion at m/z 371, confirmed the octadecadienoic acid structure. Ion fragment at $\mathrm{m} /$ z 302 provided the location of the 11,15-double bond system, and gaps of $26 \mathrm{amu}$ between $\mathrm{m} / \mathrm{z} 274-248$, and $\mathrm{m} / \mathrm{z}$ 342-316 indicated location of double bonds in positions 11 and 15, respectively (Christie, 1998).

This FA had previously been identified (Ulberth and Henninger, 1994; Precht and Molkentin, 1997, 1999) and should correspond to the cis/trans dienoic FA produced by reduction of rumelenic (cis-9,trans-11,cis-15 18:3) acid by B. fibrosolvens (Kepler and Tove, 1967). Moreover, a positive correlation between the level of trans-11,cis-15 18:2 acid and dietary supplementation of the cow diet with $\alpha$-linolenic acid containing oil has been observed (Loor et al., 2004, 2005a,b). It was shown that the biohydrogenation of cis-9,trans-11 18:2 acid into trans-11 18:1 acid in B. fibrosolvens is catalyzed by a cis-9,trans-11-octadecadienoate reductase (CLA re- 

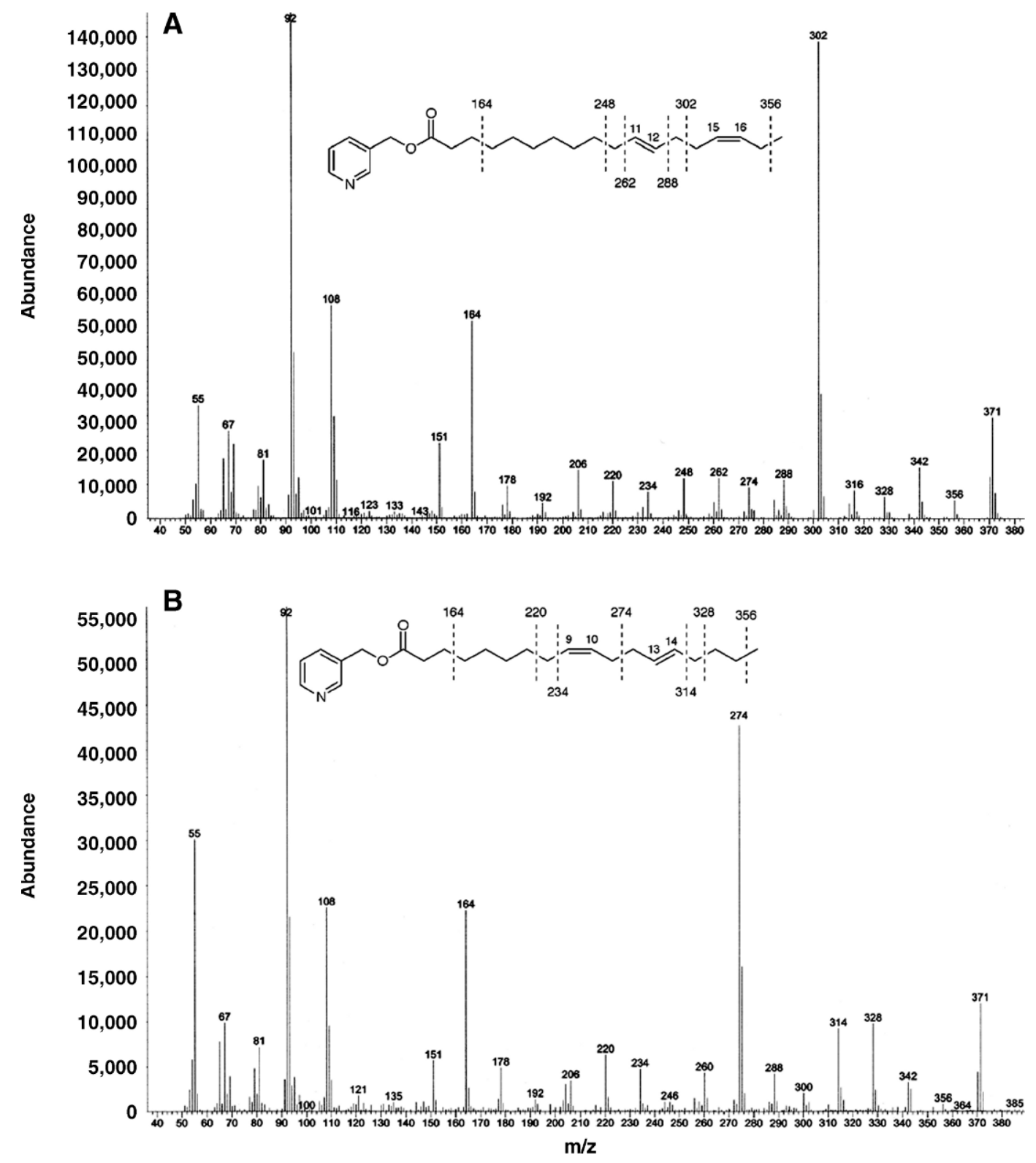

Figure 4. Mass spectra of picolinyl ester derivatives of (A) trans-11,cis-15 18:2 acid; and (B) cis-9,trans-13 18:2 acid, obtained by gas chromatography-mass spectrometry analysis of milk fat fatty acids (see Materials and Methods for detailed procedure).

ductase; Hughes et al., 1982). Therefore, it can be hypothesized that cis-9,trans-11,cis-15 18:2 acid is a substrate of the CLA reductase, which would explain previous results reported by Kepler and Tove (1967) on partially purified enzymes from $B$. fibrosolvens. By analogy to vaccenic acid, the reduction product of rumenic (cis-9,trans-11 18:2) acid, we propose vaccelenic acid as a trivial name for trans-11,cis-15 18:2 acid, the reduction product of rumelenic (cis-9,trans-11,cis-15 18:3) acid (Figure 3).

Among dienoic FA, cis-9,trans-13 18:2 acid, initially identified using a combination of infrared spectroscopy and oxidative degradation reaction (Ulberth and Henninger, 1994), is positively correlated with dietary supplementation of $\alpha$-linolenic acid (Loor et al., 2004, $2005 a, b)$. In the present study, we report the occurrence of cis-9,trans-13 18:2 acid (peak 8 in Figure 1) identified by mass spectrometry of its picolinyl ester derivative (Figure 4B). Molecular ion at $\mathrm{m} / \mathrm{z} 371$ confirmed the octadecadienoic acid structure. Ion fragment at m/z 274 indicated the location of a 9,13-double bond system, and gaps of $26 \mathrm{amu}$ between $\mathrm{m} / \mathrm{z} 234-260$ and 288-314 confirmed the location of double bonds in positions 9 and 13, respectively (Christie, 1998). 
By analogy with vaccelenic (trans-11,cis-15 18:2) acid, which is formed by reduction of rumelenic (cis9,trans-11,cis-15 18:3) acid (Kepler and Tove, 1967), it can be hypothesized that cis-9,trans-13 18:2 acid is formed by reduction of isorumelenic (cis-9,trans-13, cis15 18:3) acid in the rumen (Figure 3). The occurrence of cis-9,trans-13 18:2 acid among duodenal flow FA of cows fed $\alpha$-linolenic acid-containing oil and the positive correlation with dietary $\alpha$-linolenic acid observed (Loor et al., 2005a,b) provides indirect evidence that this FA can be formed by biohydrogenation of isorumelenic (cis9,trans-13,cis-15 18:3) acid.

Additionally, it was observed that supplementation of cow diet with $\alpha$-linolenic acid containing oil is also positively associated with an increase of trans-13/14 18:1 acid isomers (Loor et al., 2004, 2005a,b) for which baseline resolution has been achieved by GLC (Precht et al., 2001). Nevertheless, it seems that a biosynthetic relationship exists between cis-9,trans-13 18:2 and trans-13 18:1 acids and it can be hypothesized that trans-13 18:1 acid is formed by the reduction of cis9,trans-13 18:2 acid in the rumen (Figure 3).

Endogenous metabolism of trans-18:1 by $\Delta^{9}$-desaturase (or stearyl-CoA desaturase) acids has been extensively studied (Adlof et al., 2000; Griinari et al., 2000; Santora et al., 2000; Corl et al., 2002, Bauman and Griinari, 2003). Known substrates of this enzyme are saturated fatty acids, that is, 14:0, 16:0, and 18:0, but also trans-7, trans-11, and trans-12 18:1 acid isomers. Recently, it was shown that cis-9,trans-13 18:2 acid could be endogenously formed by $\Delta^{9}$-desaturation of trans-13 18:1 acid (Loor et al., 2005a,b; Figure 3). Therefore, it appears that cis-9,trans-13 18:2 acid found in milk fat could be partially formed by both ruminal biohydrogenation of $\alpha$-linolenic acid through the reduction of isorumelenic (cis-9,trans-13,cis-15 18:3) acid and endogenous $\Delta^{9}$-desaturation of trans-13 18:1 acid (Figure 3). Reduction of cis-9,trans-13,cis-15 18:3 can give rise to the formation of a conjugated trans-13,cis-15 CLA isomer which could be further reduced to trans-13 18:1 acid (Figure 3). However, trans-13,cis-15 CLA has yet to be identified in milk fat.

\section{CONCLUSIONS}

We have confirmed that conjugated isomers of $\alpha$-linolenic acid, rumelenic (cis-9,trans-11,cis-15 18:3), and isorumelenic (cis-9,trans-13,cis-15 18:3) acids are naturally present in milk fat at a combined low level (0.03\%). These results are in agreement with previous reports and provide additional support for the first steps of the biohydrogenation pathways of linoleic and $\alpha$-linolenic acids by the enzyme $\Delta^{12}$-cis, $\Delta^{11}$-trans-isomerase. Analysis of further probable biohydrogenation intermedi- ates and integration of literature data enabled us to propose a biosynthetic pathway for $\alpha$-linolenic acid ruminal biohydrogenation. Obviously, considerations regarding biological effects of rumelenic acid vis-à-vis those of rumenic acid, as well as possible $\Delta^{9}$-desaturation of vaccelenic (trans-11,cis-15 18:2) acid arise from the present study and should be further investigated.

\section{ACKNOWLEDGMENTS}

The authors are grateful to Robert L. Wolff and to the reviewers of the Journal of Dairy Science for relevant suggestions on fatty acid biosynthesis. We acknowledge financial support of Natural Sciences and Engineering Council of Canada, and of Fonds FCAR (Gouvernement du Québec). The authors are also grateful to Fondation de l'Université Laval for a Ph.D. scholarship to F. Destaillats.

\section{REFERENCES}

Adlof, R. O., S. Duval, and E. A. Emken. 2000. Biosynthesis of conjugated linoleic acid in humans. Lipids 35:131-136.

Banni, S., and J. C. Martin. 1998. Conjugated linoleic acid and metabolites. Pages 261-302 in Trans Fatty Acids in Humans Nutrition. J. L. Sébédio, and W. W. Christie, ed. The Oily Press, Dundee, UK.

Bauman, D., and J. M. Griinari. 2003. Nutritional regulation of milk fat synthesis. Annu. Rev. Nutr. 23:203-227.

Christie, W. W. 1998. Gas chromatography mass spectrometry methods for structural analysis of fatty acids. Lipids 33:343-353.

Christie, W. W., J. L. Sébédio, and P. Juanéda. 2001. A practical guide to the analysis of conjugated linoleic acid (CLA). Inform 12:147-152

Corl, B. A., L. H. Baumgard, J. M. Griinari, P. Delmonte, K. M. Morehouse, M. P. Yurawecz, and D. E. Bauman. 2002. Trans7,cis-9 CLA is synthesized endogenously by $\Delta^{9}$-desaturase in dairy cows. Lipids 37:681-688.

Destaillats, F., and P. Angers. 2002a. One-step methodology for the synthesis of FA picolinyl esters from intact lipids. J. Am. Oil Chem. Soc. 79:253-256.

Destaillats, F., and P. Angers. 2002b. Evidence for [1,5] sigmatropic rearrangements in conjugated linoleic acids in heated oils. Lipids 37:435-438.

Garrido, J. L., and I. Medina. 1994. One-step conversion of fatty acids into their 2-alkenyl-4,4-dimethyloxazoline derivatives directly from total lipids. J. Chromatogr. 673:101-105.

Griinari, J. M., B. A. Corl, S. H. Lacy, P. Y. Chouinard, K. V. Nurmela, and D. E. Bauman. 2000. Conjugated linoleic acid is synthesized endogenously in lactating dairy cows by Delta(9)-desaturase. J. Nutr. 130:2285-2291.

Hopkins, C. Y. 1972. Fatty acids with conjugated unsaturation. Pages 37-87 in Topics in Lipid Chemistry. Vol. 3. F. D. Gunstone, ed. ELEK Science, London, UK.

Hughes, P. E., W. J. Hunter, and S. B. Tove. 1982. Biohydrogenation of unsaturated fatty acids. Purification and properties of cis-9,trans11-octadecadienoate reductase. J. Biol. Chem. 257:3643-3649.

Kepler, C. R., K. P. Hirons, J. J. McNeill, and S. B. Tove. 1966. Intermediates and products of the biohydrogenation of linoleic acid by Butyrivibrio fibrisolvens. J. Biol. Chem. 241:1350-1354.

Kepler, C. R., and S. B. Tove. 1967. Biohydrogenation of polyunsaturated fatty acids III: Purification and properties of a linoleate 12-cis,11-trans isomerase from Butyrivibrio fibrisolvens. J. Biol. Chem. 242:5686-5692.

Kramer, J. K. G., P. W. Parodi, R. G. Jensen, M. M. Mossoba, M. P. Yurawecz, and R. O. Adlof. 1998. Rumenic acid: A proposed com- 
mon name for the major conjugated linoleic acid isomer found in natural products. Lipids 33:835.

Loor, J. J., A. Ferlay, A. Ollier, M. Doreau, and Y. Chilliard. 2005a. Relationship among trans and conjugated fatty acids and bovine milk fat yield due to dietary concentrate and linseed oil. J. Dairy Sci. 88:726-740.

Loor, J. J., K. Ueda, A. Ferlay, Y. Chilliard, and M. Doreau. 2004. Biohydrogenation, duodenal flow, and intestinal digestibility of trans fatty acids and conjugated linoleic acids in response to dietary forage:concentrate ratio and linseed oil in dairy cows. J. Dairy Sci. 87:2472-2485.

Loor, J. J., K. Ueda, A. Ferlay, Y. Chilliard, and M. Doreau. 2005b. Intestinal flow and digestibility of trans fatty acids and conjugated linoleic acids (CLA) in dairy cows fed a high-concentrate diet supplemented with fish oil, linseed oil, or sunflower oil. Feed Sci. Technol. 119:203-225.

Precht, D., and J. Molkentin. 1997. Effect of feeding on trans positional isomers of octadecenoic acid in milk fats. Milchwissenschaft 52:564-568.

Precht, D., and J. Molkentin. 1999. Analysis and seasonal variation of conjugated linoleic acid and further cis-/trans-isomers of C18:1 and C18:2 in bovine milk fat. Kieler Milchw. Forsch. 51:63-78.
Precht, D., J. Molkentin, F. Destaillats, and R. L. Wolff. 2001. Comparative studies on individual isomeric 18:1 acids in cow, goat, and ewe milk fats by low-temperature high-resolution capillary gas-liquid chromatography. Lipids 36:827-832.

Santora, J. E., D. L. Palquist, and K. L. Roehrig. 2000. Trans-vaccenic is desaturated to conjugated linoleic acid in mice. J. Nutr. 130:208-223.

Ulberth, F., and M. Henninger. 1994. Quantitation of trans fatty acids in milk fat using spectroscopy and chromatographic methods. J. Dairy Res. 61:517-527.

Wilde, P. F., and R. M. C. Dawson. 1966. The biohydrogenation of $\alpha$-linolenic acid and oleic acid by rumen microorganisms. Biochem. J. 98:469-475.

Wolff, R. L. 1995. Content and distribution of trans-18:1 acids in ruminant milk and meat fats. Their importance in European diets and their effect on human milk. J. Am. Oil Chem. Soc. 72:259-272.

Wolff, R. L., and W. W. Christie. 2002. Structures, practical sources (gymnosperm seeds), gas-liquid chromatographic data (equivalent chain lengths), and mass spectrometric characteristics of allcis 5-olefinic acids. Eur. J. Lipid Sci. Technol. 104:234-244. 